\title{
Prediction of the Slag Corrosion of MgO-C Ladle Refractories by the Use of Artificial Neural Networks
}

\author{
S. Akkurt \\ Mechanical Engineering Department, Izmir Institute of Technology, Izmir, 35437, Turkey
}

Keywords: MgO-C refractory, corrosion, prediction, model, artificial neural networks.

\begin{abstract}
A multilayer feed-forward back-propagation learning algorithm was employed as an artificial neural network (ANN) tool to create a model to predict the corrosion of $\mathrm{MgO}-\mathrm{C}$ ladle refractory bricks based on laboratory slag corrosion test data. The corrosion process occurred by immersion of the rectangular refractory specimens in molten slag-steel bath. An ANN model to predict the amount of corrosion was created by using the training data. The model was also tested with experimentally measured data and relatively low error levels were achieved. This model was then used to predict the response of the slag-corrosion system to different values of the factors affecting the corrosion of bricks at high temperatures. Exposure time, exposure temperature of slagbrick contact and $\mathrm{CaO} / \mathrm{SiO}_{2}$ ratio of the slag were the factors used for modelling. Model results provided the potential for selection of the best conditions for avoiding the factor combinations that may accelerate corrosion.
\end{abstract}

\section{Introduction}

$\mathrm{MgO}-\mathrm{C}$ refractories are extensively used in slag-lines of primary steelmaking vessels and secondary refining ladles. Their service lives are now as high as 30000 in Basic Oxygen Furnaces (BOF) compared to significantly lower lives of as low as 25 heats/lining in ladle refining furnaces. Factors affecting the corrosion of these bricks were previously investigated in a number of studies $[1,3]$. Some of the main corrosion parameters are the presence of a slag coating on the brick, the brick microstructure, the quality of brick components like periclase grains, type of antioxidants, graphite flakes, the resin used, thermomechanical loads, slag chemistry, viscosity and so on.

It is theoretically possible to produce a wear model based on laboratory tests and then to correlate that model to actual furnace practice. The precision that can be achieved by any wear model is directly related to the precision of the data used to develop that model. Predictive models can be made from laboratory experiments provided the data are statistically significant and have a known and small variance [4]. There are two approaches to modelling of refractory corrosion: models based on laboratory tests and those based on industrial data. In the former case, the scale of the test and the dynamics are significantly different from those that occur in an actual production furnace but more controlled and fundamental data can be generated. In the latter case, a large number of replications is required to get precision and a large spead of data (e.g.10-50\% variation) is common. Artifical neural networks (ANN) are ideally suited for modelling such systems.

In a recent study, a statistical experimental design technique was used for modelling the corrosion process [5]. The effects of factors like time, temperature and slag chemistry on corrosion were reported in that study. Data obtained in that work are employed in this research by feeding them to an ANN simulator algorithm to create a model for the prediction of the corrosion of industrial MgO$\mathrm{C}$ ladle refractory bricks in molten steel refining slags. ANN are used for modelling complex systems in a wide range of fields [6-7]. Most ceramic and refractories related projects (e.g. 
refractory processing, particle sizing, drying, firing, etc.) involve the study of the effects of selected parameters like time, temperature, pressure on a response (e.g. density, porosity, hot strength, corrosion resistance). Such processes can be modelled by ANN by feeding plant data in the model construction. The model can then be used to predict the response of the system to different parameter combinations. Steelmakers can determine the potential problem areas by using the ANN model developed here or they can use their data to create a model for their particular system.

\section{ANN Modelling}

In the present study, the common three layer, feed forward type of ANN, as shown in Fig. 1, was adopted for the prediction of the amount of corrosion. In a feedforward network, the inputs are fed into the input layer, which passes them on to the hidden layer neurons after multiplying by a weight. A hidden layer neuron adds up the weighted input received from each input neuron, associates it with a bias, and then passes the result on through a non-linear transfer function. The same operation is done in the output layer [7].

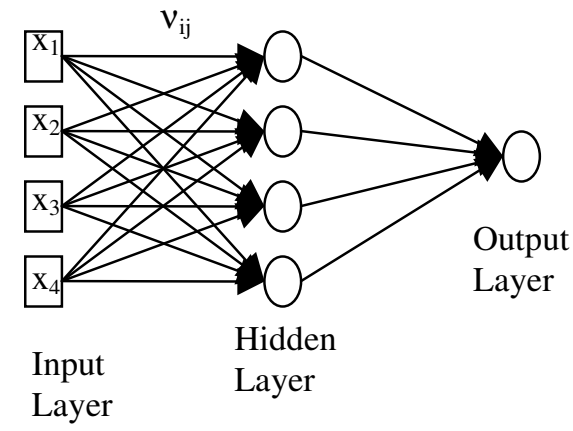

Figure 1. The three-layer ANN model [6].

ANN can be trained by back-propagation (BP), which is the most commonly used supervised training algorithm. In back-propagation networks, inputs are processed in the forward direction from the input layer to the hidden layer and then to the output layer (Fig. 1). The objective of a back propagation network is, by minimizing a predetermined error function, to find the optimal weights which would generate an output vector $\boldsymbol{Y}=\left(y_{1}, y_{2}, \ldots, y_{p}\right)$ as close as possible to target values of output vector $\boldsymbol{T}=\left(t_{l}\right.$, $\left.t_{2}, \ldots, t_{p}\right)$ with a selected accuracy. Detailed

[7] information regarding the ANN can be found in reference. Development of an ANN model involves the use of training and testing data sets that are only random selections from the complete original data. The model is first trained and then tested with measured data to determine the error of the model.

Data collection. The data used in ANN modelling had been collected from the corrosion testing setup in a previous study of the author, and the resulting data were modelled using statistical methods [3,5]. Characterization of the same bricks were also performed in a previous study [8]. The tests were conducted in an argon and/or $\mathrm{CO}(\mathrm{g})$ atmosphere in a vertical tube furnace that was heated by $\mathrm{MoSi}_{2}$ heating elements. $1.4 \times 1.4 \times 7 \mathrm{~cm}$ sized rectangular brick specimens attached to a calcium aluminate cement holder were half immersed in the slag melt for a prescribed amount of time. The slag melt was kept in a high alumina crucible which was placed in a larger safety crucible. The tests were done without rotating the samples although rotation was possible in the experimental setup. Upon completion of each run the samples were raised up and kept there until the furnace cooled. Samples were then longitudinally cut in half, mounted in polyester resin and polished to determine percent area loss by corrosion. All data are listed in Table 1.

Model Construction. The ANN architecture that was constructed was of three layer feed forward type with six neurons in the input layer for the six input variables. In the hidden layer, six neurons were chosen by trial and error. Finally, in the output layer one neuron was chosen for the output variable of percent area loss. The input variables were as follows: 
$\mathrm{x}_{1}: \% \mathrm{CO}(\mathrm{g})$ in test atmosphere,

$\mathrm{x}_{2}$ : Brick-slag exposure time, min.

Table 1. Experimental data used in ANN model building.

\begin{tabular}{|c|c|c|c|c|c|}
\hline & \multicolumn{4}{|c|}{ Input parameters } & Output $(\boldsymbol{T})$ \\
\hline $\begin{array}{l}\text { Exp } \\
\text { No. }\end{array}$ & $\% \mathrm{CO}$ & $\begin{array}{l}\text { Time } \\
(\min )\end{array}$ & $\mathrm{T}\left({ }^{\circ} \mathrm{C}\right)$ & $\mathrm{C} / \mathrm{S}^{*}$ & $\begin{array}{c}\% \text { Area } \\
\text { Loss } \\
\text { (Measured) }\end{array}$ \\
\hline 1 & 0 & 100 & 1640 & 1.7 & 41.22 \\
\hline 2 & 0 & 100 & 1600 & 1.7 & 20.08 \\
\hline 3 & 0 & 20 & 1640 & 1.7 & 22.82 \\
\hline 4 & 0 & 100 & 1620 & 0.9 & 15.23 \\
\hline 5 & 0 & 20 & 1620 & 0.9 & 18.89 \\
\hline 6 & 0 & 20 & 1620 & 2.6 & 2.97 \\
\hline 7 & 0 & 60 & 1600 & 0.9 & 24.83 \\
\hline 8 & 0 & 60 & 1600 & 2.6 & 17.41 \\
\hline 9 & 0 & 60 & 1620 & 1.7 & 16.18 \\
\hline 10 & 0 & 60 & 1620 & 1.7 & 14.26 \\
\hline 11 & 0.05 & 100 & 1640 & 1.7 & 30.87 \\
\hline 12 & 0.05 & 100 & 1600 & 1.7 & 18.85 \\
\hline 13 & 0.05 & 20 & 1640 & 1.7 & 21.14 \\
\hline 14 & 0.05 & 20 & 1600 & 1.7 & 12.55 \\
\hline 15 & 0.05 & 100 & 1620 & 2.6 & 10.73 \\
\hline 16 & 0.05 & 20 & 1620 & 0.9 & 18.43 \\
\hline 17 & 0.05 & 20 & 1620 & 2.6 & 6.28 \\
\hline 18 & 0.05 & 60 & 1640 & 0.9 & 12.55 \\
\hline 19 & 0.05 & 60 & 1640 & 2.6 & 15.47 \\
\hline 20 & 0.05 & 60 & 1600 & 0.9 & 24.03 \\
\hline 21 & 0.05 & 60 & 1600 & 2.6 & 3.98 \\
\hline 22 & 0.05 & 60 & 1620 & 1.7 & 16.65 \\
\hline 23 & 0.05 & 60 & 1620 & 1.7 & 15.25 \\
\hline
\end{tabular}

$\mathrm{x}_{3}$ : Test temperature $\left({ }^{\circ} \mathrm{C}\right)$

$\mathrm{x}_{4}: \mathrm{CaO} / \mathrm{SiO}_{2}$ ratio of the slag

This is shown in Figure 1 where the four input quantities are fed to the leftmost column. Neurons are fully connected to each node in the neighboring layers. No bias term was used but a momentum term was used to help to obtain faster convergence during iterations. A total of 30 data sets were employed, of which 23 were used for the training of the ANN and the remainder for testing of the model. Each data set had 5 components $(\mathrm{x} 1, \mathrm{x} 2, \ldots, \mathrm{x} 4 ; \mathrm{y}) 4$ of which were the input variables while the fifth one is the output variable. The program operated for 80000 iterations and the optimal weights were successfully calculated $\left(r^{2}=0.89\right)$.

Testing phase. Because of the limited number of experimental data only seven testing outputs were compared to measured data (Table 2). The performance of the model was quite satisfactory with average percent testing error of $14.2 \%\left(r^{2}=0.92\right)$.

Sensitivity analysis. Sensitivity analysis is done by feeding the developed ANN model to predict outputs (percent area loss) for varying levels of the input factor effects (time, temperature and C/S). In this study, combined effects of two factors are presented to save space. During the sensitivity analysis the temperature range of $1600-1640^{\circ} \mathrm{C}$ and the time range of (0-100 minutes) were divided into 10 subdivisions, and a total of 100 predicted percent area loss values were obtained (Fig. 2). Similar procedure is applied for the other two factor combinations.
Table 2. Results of testing of the model.

\begin{tabular}{lccc}
\hline $\begin{array}{l}\text { \% Area loss } \\
\text { (measured) }\end{array}$ & $\begin{array}{c}\text { \% Area loss } \\
\text { (predicted) }\end{array}$ & Difference & $\begin{array}{l}\text { \%Error } \\
\text { (Absolute) }\end{array}$ \\
\hline 10.57 & 12.43 & -1.86 & 17.6 \\
10.85 & 14.57 & -3.72 & 34.3 \\
14.65 & 14.85 & -0.20 & 1.4 \\
18.99 & 18.94 & 0.05 & 0.3 \\
19.20 & 18.05 & 1.15 & 6.0 \\
32.34 & 24.80 & 7.54 & 23.3 \\
15.67 & 18.27 & -2.60 & 16.6 \\
\hline & & Average & 14.2
\end{tabular}

Only two of the dual factor surface plots are given here for the sake of brevity. Sensitivity analysis enables researcher or plant operator to quickly identify the experimental conditions for highest wear so that he can avoid problem areas. Figs. 2-3, based on the results of prediction runs of the ANN model, show the effects of two factors at a time on each surface plot of the percent area loss. The effects of time and temperature on percent area loss in argon atmosphere is shown in Fig. 2. The increasing temperature leads to an increase of percent area loss at all levels of time. Insignificant interaction is observed between time and temperature

factors. Fig. 3 shows a surface plot of the effects of $\mathrm{C} / \mathrm{S}$ ratio and temperature on percent area loss in argon $+\mathrm{CO}(\mathrm{g})$ atmosphere. Relationships observed between factor effects and the percent area loss by the above mentioned plots conform to the general understanding of corrosion systems. Such plots are especially useful when a researcher seeks interactions between factor effects and a visual way of inspecting system behavior. 


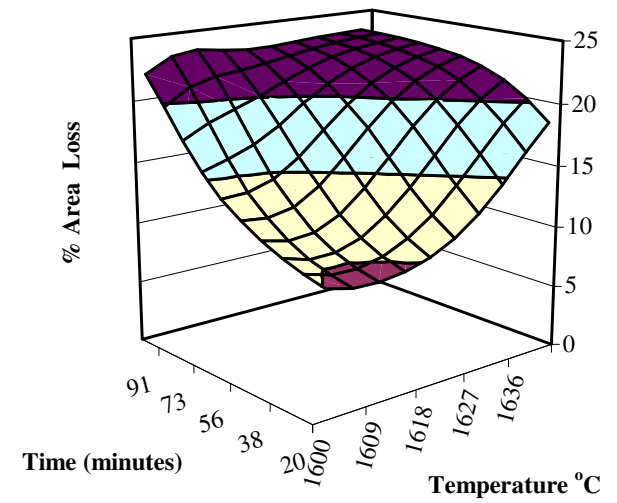

Figure 2. Time-temperature surface plot for percent area loss in argon atmosphere.

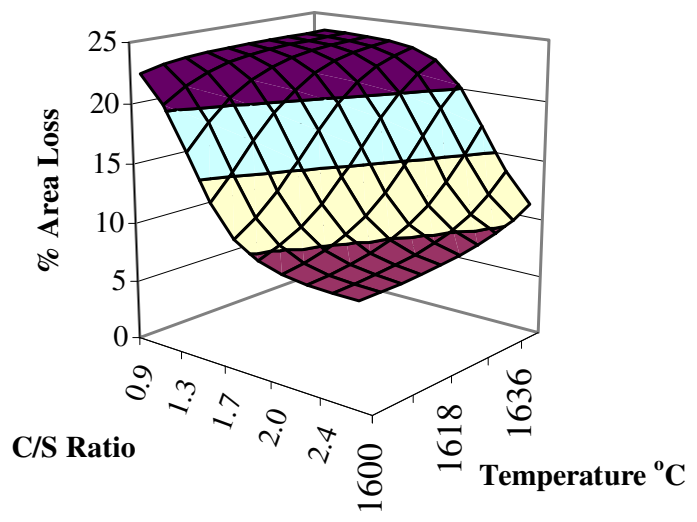

Figure 3. $\mathrm{CaO} / \mathrm{SiO}_{2}$-temperature surface plot for percent area loss in $\mathrm{Ar}+5 \% \mathrm{CO}$ atmosphere.

\section{Conclusions}

In this study, a three layer ANN model is developed for the prediction of percent area loss in a laboratory slag corrosion system of $\mathrm{MgO}-\mathrm{C}$ ladle refractories. The satisfactory predictions of the observed percent area loss by the model indicates that ANN could be a useful tool for modelling refractory corrosion systems.

ANN modelling is able to produce surface plots to visually understand the system via sensitivity analysis. Consequently, the model could be utilized by plant operators to avoid potentially corrosive factor combinations during plant operations. Using an extension of this approach, large numbers of plant data on refractory recess thickness, slag chemistry, number of heats per day, type of steel, slag/steel volume ratio, tap-to-tap time and temperature, and the degree of mixing of ladle can be used to create a model to predict refractory corrosion.

\section{References}

[1] S.Zhang, N.J. Marriott and W.E.Lee: J. Eu. Cer. Soc. Vol.21 (2001) 1037-1047

[2] W.E.Lee and S. Zhang: Intl. Matls. Revs., Vol.44, [3] (1999), 77-104.

[3] S. Akkurt, "Investigation of the corrosion of MgO-C ladle refractories via a laboratory slag test", PhD Dissertation, Clemson University, USA, August 1998.

[4] H.D.Leigh, Private communication, 2003.

[5] S. Akkurt and H.D.Leigh, in press, Am. Cer. Soc. Bull., Vol. 82, No:5, May 2003.

[6] S.Akkurt, S.Ozdemir and G.Tayfur, Trans of IMM, Vol. 111, No:3, C129-C134, 2003.

[7] T. Munakata, Fundamentals of the new AI: Beyond traditional paradigms, (Springer-Verlag, New York, 1998).

[8] S. Akkurt and H.D.Leigh, J. Can. Cer. Soc., Vol. 71, 9-18, Fall 2002. 


\section{Euro Ceramics VIII}

10.4028/www.scientific.net/KEM.264-268

Prediction of the Slag Corrosion of MgO-C Ladle Refractories by the Use of Artificial Neural Networks 10.4028/www.scientific.net/KEM.264-268.1727 